\title{
TECNOLOGIAS E SISTEMAS DE INFORMAÇÃO: uma área científica orientada às necessidades de conhecimento dos profissionais envolvidos na contínua transformação das organizações através das tecnologias da informação
}

\author{
INFORMATION SYSTEMS AND TECHNOLOGY: a scientific area oriented to \\ the knowledge needs of professionals involved in the continuous transformation \\ of organizations through information technology
}

João Álvaro Carvalho Departamento de Sistemas de Informação e Centro Algoritmi Escola de Engenharia

Universidade do Minho, Portugal jac@dsi.uminho.pt

\begin{abstract}
RESUMO
Tecnologias e sistemas de informação é a área científica de enquadramento para aqueles que se interessam, académica ou profissionalmente, pela adopção e exploração de tecnologias da informação no contexto das organizações ou da sociedade. É uma área que emergiu como consequência da importância que as TI tem vindo a assumir nas actividades humanas que envolvem alguma forma de processamento de informação. Dada a sua forte interligação com outras áreas, as suas fronteiras são de difícil delimitação. As actividades dos profissionais de TSI e as suas necessidades de conhecimento são usadas neste artigo como critério para definir o âmbito da área científica. Assim, após uma caracterização das actividades profissionais de TSI, são apresentados os grandes grupos que constituem o corpo de conhecimento da área e são apresentados os principais métodos de I\&D usados na produção de novo conhecimento cientificamente válido.
\end{abstract}

PALAVRAS-CHAVE: Tecnologia da informação. Sistemas de informação. Perfis profissionais. Organização do conhecimento.

\section{INTRODUÇÃO}

Tecnologias e sistemas de informação (TSI) é a designação usada neste artigo para referir a área científica de enquadramento para aqueles que se interessam, académica ou profissionalmente, pela adopção e exploração de tecnologias da informação (TI) no contexto das organizações ou da sociedade. Também designada por sistemas de informação ou sistemas de informação de gestão (management information systems - MIS), esta área científica não é fácil de delimitar. Poderá dizer-se que a área emerge como consequência da importância que as TI tem vindo a assumir nas actividades humanas que envolvem alguma forma de processamento de informação, particularmente no contexto organizacional, mas não só. A área está alicerçada em saberes construídos em áreas da tecnologia (informática), das ciências humanas (cognição, linguagem) e das ciências sociais (informação, comunicação, comportamento organizacional, organização, economia). Ao longo dos anos, vários debates têm posto em evidência a dificuldade em identificar "o" objecto desta área científica e a grande (talvez exagerada) diversidade de métodos de I\&D que são usados nas actividades que visam expandir o corpo de conhecimento da área. Por estas razões, a própria identidade da

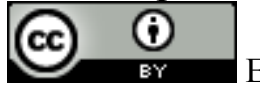

Esta obra está licenciada sob uma Licença Creative Commons.

DOI 10.5007/1518-2924.2010v15nesp2p1

Enc. Bibli: R. Eletr. Bibliotecon. Ci. Inf., Florianópolis, n. esp., $2^{\circ}$ sem. 2010. ISSNe 1518-2924 
área científica tem sido posta em causa. De qualquer modo são muitos os artigos que se debruçam sobre a sua natureza, problemas e desafios (BANVILLE et al., 1989, KHAZANCHI; MUNKVOLD, 2000, NIEDERMAN, 2007, SIDOROVA et al. 2008, HARDAWAY; MATHIEU; WILL, 2008, NEVO; NEVO; EIN-DOR, 2009)

Para efeitos da caracterização da área científica de TSI, vão ser distinguidos três aspectos complementares: (i) o corpo de conhecimento da área; (ii) os métodos de $I \& D$ usados por aqueles que contribuem para o desenvolvimento daquele corpo de conhecimento; (iii) as actividades profissionais cuja capacidade para criar valor dependem daquele corpo de conhecimento.

Assume-se ainda que as actividades dos profissionais de TSI constituem critério adequado para definir o âmbito da área científica. Compreendendo as necessidades de conhecimento destas actividades será possível delimitar o corpo de conhecimento da área. E também compreender a diversidade de fenómenos/objectos de interesse e de métodos de I\&D utilizados.

Assim, seguindo aquela perspectiva, apresentam-se e justificam-se as principais actividades profissionais que são da competência dos profissionais de TSI, serão apresentados os grandes grupos que constituem o corpo de conhecimento da área e será apresentada uma justificação para a utilização de uma gama alargada de métodos de I\&D usados na produção de novo conhecimento cientificamente válido.

\section{MISSÃO DOS PROFISSIONAIS DE TSI}

A utilização das TI não é um fim em si mesmo. As TI são necessárias e úteis nas organizações na medida em que contribuem para a sua eficácia, eficiência e sustentabilidade. As TI são pois instrumentais nas actividades das organizações. É no entanto inegável que os desenvolvimentos e inovações ao nível das TI têm sido o motor de muitas das mudanças a nível das organizações e da sociedade. Do mesmo modo que no século XVIII a máquina a vapor desencadeou a evolução que levou às mudanças hoje em dia designadas por revolução industrial, o computador moderno desencadeou no século XX a evolução que nos trouxe para a sociedade da informação. Se no primeiro caso esteve em causa a amplificação das capacidades físico-motoras dos seres humanos, o que agora está em causa é a amplificação das suas capacidades cognitivas. Justifica-se assim o emergir de uma nova área científica em que as TI são centrais a um conjunto de fenómenos organizacionais e sociais e a um conjunto de intervenções que, em última análise, estão relacionadas com o bem estar das organizações e da sociedade.

As TI estão presentes em situações organizacionais que envolvem informação. Trata-se portanto de situações de natureza humana e social já que a informação é, também ela, um fenómeno humano e social. Lidar com a adopção e exploração das TI nas organizações envolve pois um corpo alargado de conhecimento de natureza multidisciplinar, abrangendo aspectos tais como: as TI; a informação; os fenómenos humanos e sociais associados à produção, processamento e utilização da informação; os fenómenos da adopção e utilização das TI; aspectos comportamentais, ao nível dos indivíduos, dos grupos, das organizações relevantes para os contextos da adopção e utilização das TI e suas aplicações; os métodos 
técnicas e ferramentas aplicáveis na condução de actividades de gestão e de intervenção organizacional relacionadas com a adopção e exploração das TI nas organizações.

A dinâmica da sociedade actual - simultaneamente consequência e causa dos constantes desenvolvimentos das TI - e a complexidade da operação e da gestão das organizações modernas coloca as organizações e a sociedade ${ }^{1}$, face a novos problemas e desafios, directamente relacionados com as $\mathrm{TI}$ :

a) As organizações sentem a necessidade de se manterem aptas para competirem com as suas congéneres, procurando utilizar práticas organizacionais que configuram níveis de eficiência similares (ou superiores) às dos seus competidores; esta eficiência é em grande parte afectada pelo suporte proporcionado pelas TI;

b) Ao longo das últimas décadas têm vindo a emergir "pacotes" (packages) de aplicações informáticas cuja aceitação alargada configura situações de normas de facto aplicáveis a determinados segmentos de mercado; a sua adopção e uso tornam-se assim um imperativo para as organizações;

c) São frequentes as inovações que viabilizam o aparecimento de novas aplicações informáticas que, em muitos casos, levam a substanciais mudanças no modo de organizar o trabalho;

d) Outras inovações têm viabilizado novos negócios, nomeadamente aqueles em que o produto negociado é informação;

e) A crescente globalização das actividades económicas cria novas necessidades de interacção entre empresas e, consequente, a necessidade de interoperabilidade das respectivas aplicações informáticas;

f) As constantes mudanças das configurações empresariais, com frequentes fusões e autonomizações de unidades económicas, aumentam significativamente os desafios de integração e de interoperabilidade das respectivas aplicações informáticas;

g) A complexidade das plataformas e das aplicações informáticas, a diversidade de produtos e a existência de diversos paradigmas de implementação das plataformas e das aplicações cria situações de difícil compatibilização, interoperabilidade, escalabilidade, capacidade de evolução e manutenção;

h) Os computadores e as aplicações informáticas estão cada vez mais presentes no dia a dia das pessoas, não só nos contextos de trabalho, mas também nos de educação, lazer, entretenimento e ainda no relacionamento entre pessoas e entre pessoas e empresas e instituições;

i) A evolução da sociedade e o crescimento da capacidade dos cidadãos na utilização de meios informáticos criam novos comportamentos e expectativas sociais com que as empresas têm que lidar.

É missão dos profissionais de TSI ajudar as organizações a lidar com estas questões e a enfrentar estes desafios. Trata-se de profissionais cujo trabalho está relacionado com as TI, mas cuja responsabilidade é sobretudo o de facilitar a contínua transformação das organizações através da adopção e exploração de TI. Transformações essas que se envolvem disponibilização de informação a situações de trabalho intelectual (knowledge work) e cujo

\footnotetext{
Embora primeiramente focado nas organizações, as questões relacionadas com a adopção e utilização das TI e com o consequente impacto, estendem-se naturalmente a um contexto mais alargado, o contexto da sociedade em geral. Assim, as questões aqui levantadas aplicam-se também ao nível da sociedade. E aqui assume particular importância o papel que desempenham as organizações com responsabilidade na gestão da sociedade - os governos - quer estes actuem ao nível local, regional, nacional ou ainda internacional, no seu papel de regular e influenciar o comportamento de indivíduos, grupos ou organizações.

Enc. Bibli: R. Eletr. Bibliotecon. Ci. Inf., Florianópolis, n. esp., $2^{\circ}$ sem. 2010. ISSNe 1518-2924
} 
sucesso é medido pela satisfação dos clientes da organização ou pelo desempenho da organização ${ }^{2}$.

\section{TECNOLOGIAS DA INFORMAÇÃO NAS ORGANIZAÇÕES}

Desde a sua introdução nas organizações, no final dos anos 1950 (EIN-DOR; SEGEV, 1993), a utilização dos computadores no suporte às actividades organizacionais tem vindo a alargarse. Das aplicações iniciais focadas na produção automática de resultados informacionais (processamento de dados ou informação de gestão), a utilização das TI baseadas em computadores nas organizações tem vindo a expandir-se para todas as actividades organizacionais, abrangendo aspectos tais como:

a) Apoio à execução, em tempo real, das transacções organizacionais, quer externas (transacções que envolvem interacção com os clientes, fornecedores ou outras entidades do ambiente organizacional), quer internas (transacções que envolvem interacção entre entidades internas à organização) - processamento de transacções em tempo real (OLTP on line transaction processing);

b) Este tipo de apoio envolve a criação e actualização dos registos organizacionais que reflectem a ocorrência das transacções e as suas consequências no estado 'das coisas' (state of affairs) da organização;

c) Alargamento da diversidade de canais para a realização das 'transacções comerciais' de uma organização, facilitando a disponibilização permanente e globalizada do acesso aos bens ou serviços da organização (comércio electrónico);

d) Produção automática de resultados informacionais, para uso externo ou interno, quer numa lógica de informação para fins operacionais (processamento de dados) quer na lógica da produção de informação de gestão. Em ambos os casos está em causa a execução automática de operações dedutivas;

e) Disponibilização de plataformas de suporte à gestão, quer no que respeita a acesso a informação sobre a situação da organização, quer no acesso e utilização de modelos de decisão e de resolução de problemas, quer ainda ao registo, divulgação e acompanhamento das decisões tomadas. De forma geral poderão ser descritas como as actividades associadas ao comando e controlo organizacional. Inclui-se no primeiro caso o suporte ao trabalho dos gestores através da disponibilização de ferramentas de análise de informação em tempo real (OLAP - on line analytical processing). No segundo caso inclui-se o trabalho organizacional que envolve a simulação de cenários alternativos, explorando de modelos de decisão ou algoritmos de resolução de problemas e ainda os processos de tomada de decisão que envolvem a participação de várias pessoas, nomeadamente através de vários tipos de votações (sistemas de apoio à decisão). No que respeita à divulgação de informação relacionada com decisões, inclui-se toda a comunicação de 1 para 1 ou de 1 para muitos e ainda a memorização e partilha de documentos que descrevem as decisões tomadas;

f) Recolha automática de informação dos mercados e dos concorrentes numa lógica de vigilância competitiva (competitive intelligence);

g) Descoberta automática de padrões e tendências nos comportamentos de clientes ou nos fenómenos relevantes do 'negócio' baseada nos registos das transacções organizacionais (descoberta de conhecimento em bases de dados e data mining);

\footnotetext{
2 Esta definição do trabalho dos profissionais de TSI é inspirada em BACON, C. J.; FITZGERALD, B. A systemic framework for the field of information systems. The Data BASE for Advances in Information Systems, v. 32, n. 2, 2001, p 46-67.

Enc. Bibli: R. Eletr. Bibliotecon. Ci. Inf., Florianópolis, n. esp., $2^{\circ}$ sem. 2010. ISSNe 1518-2924.
} 
h) Coordenação do trabalho organizacional através do recurso a plataformas de gestão do fluxo de trabalho que permitem orquestrar a execução do trabalho, distribuindo tarefas a pessoas e aplicações informáticas, lidando com os documentos associados à execução do trabalho (workflow management systems e document management systems);

i) Colaboração entre pessoas, através do estabelecimento de canais de comunicação, formais e informais, e da partilha de documentos;

j) Relacionamento entre pessoas, envolvendo troca de mensagens e partilha de documentos relacionados não só com questões estritas do trabalho organizacional mas também com aspectos de interesse de grupos mais restritos (por exemplos grupos profissionais) ou ainda manifestações de emoções e outras formas de relacionamento social;

k) Arquivo geral de informação da organização, nomeadamente de documentos associados à execução do trabalho ou de qualquer outra informação;

1) Viabilização de actividades organizacionais emergentes tais como a gestão do relacionamento com os clientes (CRM - customer relationship management) ou a gestão da cadeia de fornecimento (SCM - supply chain management). Tais actividades organizacionais só são possíveis graças à combinação de diversas capacidades computacionais e/ou comunicacionais proporcionadas pelas TI;

m) Suporte ao estabelecimento e divulgação de boas práticas organizacionais e ao desenvolvimento das capacidades de trabalho da organização na lógica de preocupações organizacionais tais como design organizacional, qualidade, gestão do conhecimento;

n) Suporte ao estimular das capacidades de inovação da organização através da dinamização de interacções entre pessoas internas e/ou externas à organização;

o) Amplificação das capacidades cognitivas individuais das pessoas através de ferramentas informáticas para armazenamento, processamento, distribuição, partilha, pesquisa e apresentação de informação utilizada a nível individual;

p) Prestação de contas aos accionistas ou à sociedade através da disponibilização de informação sobre o estado da organização.

Faz ainda sentido referir o crescente espaço de negócio constituído por empresas cujos produtos assentam essencialmente sobre informação - serviços de informação - que, consequentemente, são utilizadores intensivos das TI.

Esta diversidade de papéis desempenhados pelas TI nas organizações convida a um mudar de perspectiva sob o modo como as TI devem ser tratadas nas organizações. Hoje em dia, qualquer que seja a actividade organizacional em causa, envolve com certeza alguma forma de informação e, consequentemente, é susceptível de contar com o envolvimento de TI. Assim, poderá dizer-se que pessoas e $T I$ simultaneamente cooperam e competem na execução de trabalho organizacional. O design de estruturas de trabalho contempla assim a procura de um equilíbrio, sempre provisório, na distribuição do trabalho entre aquelas duas entidades com capacidade de executar trabalho.

O levar um pouco mais longe esta perspectiva conduz-nos ao conceito de mente organizacional, uma exploração metafórica do conceito de mente aplicada às capacidades intelectuais e cognitivas das organizações (RAMOS; CARVALHO, 2006, CARVALHO; RAMOS, 2006, RAMOS; CARVALHO, 2007, RAMOS; CARVALHO, 2008). Na mente organizacional a execução das funções da inteligência - percepção, atenção, memória, produção de pensamentos, raciocínio, conhecimento, utilização da linguagem, aprendizagem, imaginação, inovação - está distribuída entre pessoas e TI. No entanto, ao contrário do que acontece na mente humana, esta distribuição não acontece espontaneamente. Ela carece de Enc. Bibli: R. Eletr. Bibliotecon. Ci. Inf., Florianópolis, n. esp., 2º sem. 2010. ISSNe 1518-2924. 
atenção por parte de 'organizadores' e 'coordenadores', actuando no âmbito de actividades tais como design e desenvolvimento organizacional, gestão do conhecimento da aprendizagem e da inovação, ou ainda de outras funções organizacionais.

De notar que a cota parte de responsabilidade das TI na mente organizacional tem vindo a aumentar. E continuará a aumentar fruto do desenvolvimento de capacidades, actualmente ainda incipientes, resultantes da combinação de aspectos tecnológicos tais como: raciocínio automático; estabelecimento de associações entre informação dispersa (não só internamente à organização, mas também na Web) pela atribuição automática de significado; novas formas de interacção com dispositivos informáticos; exploração de redes sociais; computação ubíqua. Este aumento do papel desempenhado pelas TI traduz-se não no assumir da execução de funções organizacionais já existentes mas também no fazer emergir novas funções organizacionais potenciadas pelas TI.

\section{CATEGORIAS DE TI NAS ORGANIZAÇÕES}

Os exemplos atrás referidos, ilustram diferentes formas de participação das TI no trabalho organizacional. Por detrás das TI mais directamente perceptíveis no contexto da execução do trabalho organizacional, outras formas de TI são também necessárias. As TI organizacionais poderão assim ser enquadradas em três grandes categorias, cada uma delas com exigências e preocupações diferentes:

\section{a) Aplicações informáticas}

Nesta categoria incluem-se as tecnologias que participam directamente na execução de trabalho organizacional. Tal como anteriormente foi referido, tal envolvimento pode estar associado a qualquer forma de trabalho organizacional, à viabilização de canais comerciais, automatização de tarefas informacionais, extensão das capacidades cognitivas humanas, coordenação do trabalho ou outros.

Muitos destes produtos informáticos são hoje em dia disponibilizados como serviços, acessíveis a partir de browsers $\mathrm{Web}^{3}$.

Por outro lado, o acesso a estas aplicações envolve muitas vezes dispositivos terminais dedicados, fixos ou móveis, concebidos especificamente para a situação em causa.

\section{b) Plataformas para aplicações informáticas}

O amadurecimento das tecnologias de informação levou ao aparecimento de plataformas diversas que facilitam a criação e disponibilização de aplicações informáticas. Poderão considerar-se vários tipos de plataformas, tais como:

(i) tecnologias de armazenamento, recuperação, navegação e interoperabilidade de informação. Incluem os sistemas de gestão de bases de dados, de data warehousing, software OLAP; e também as normas, protocolos e plataformas da Web semântica;

(ii) tecnologias de raciocínio e inteligência automáticos. Incluem software de análise automática de registos (data mining) e outras formas de raciocínio e aprendizagem automáticos baseados em técnicas de inteligência artificial;

\footnotetext{
${ }^{3}$ Note-se que o browser, independentemente de ele próprio poder ser considerado uma aplicação informática, tem vindo a tornar-se o modo de aceder a quaisquer outras aplicações informáticas ou serviços.

Enc. Bibli: R. Eletr. Bibliotecon. Ci. Inf., Florianópolis, n. esp., $2^{\circ}$ sem. 2010. ISSNe 1518-2924.
} 
(iii) tecnologias de visualização de informação e interacção humano-computador. Inclui tecnologia que facilita a produção de representações baseadas em informação recolhida, armazenada e processada pela organização bem como tecnologia que facilita a criação de formas de interacção entre pessoas e computadores por forma a que a utilização de TI no âmbito do trabalho organizacional esteja tão ajustada quanto possível às características do trabalho e das pessoas que participam na execução desse trabalho.

\section{c) Plataformas de computação e comunicações}

Inclui os dispositivos base de computação e comunicações, incluindo servidores e equipamentos de comunicações e respectivo software (p. ex.: sistemas operativos, software de comunicações).

Do ponto de vista do negócio, esta componente pode ser apresentada como infra-estrutural. Aliás, tudo aponta para que a capacidade de computação e comunicações se assuma cada vez mais como uma commodity, à semelhança do que acontece, por exemplo, com a energia eléctrica (CARR, 2008).

Por forma a facilitar o modo como as capacidades de computação e comunicações são disponibilizadas à organização, esta componente pode ser tratada como um serviço. Teremos assim os serviços de computação e comunicações. Tais serviços poderão ser geridos internamente pela organização ou podem ser obtidos de entidades terceiras. No primeiro caso, tais serviços poderão ser equiparados a outros serviços infra-estruturais existentes nas organizações que visam garantir o bom funcionamento de aspectos tais como instalações e commodities. Em qualquer dos casos pretende-se que a computação seja ubíqua, i.e., que esteja disponível onde e quando necessário, quer em locais específicos quer no contexto de actividades que envolvem mobilidade.

A figura 1 apresenta estas categorias de TI numa disposição em camadas que procura sugerir a existência de dependências entre elas. Com efeito, as aplicações informáticas dependem das plataformas para aplicações informáticas, e estas, por sua vez, dependem dos serviços de computação e comunicações.
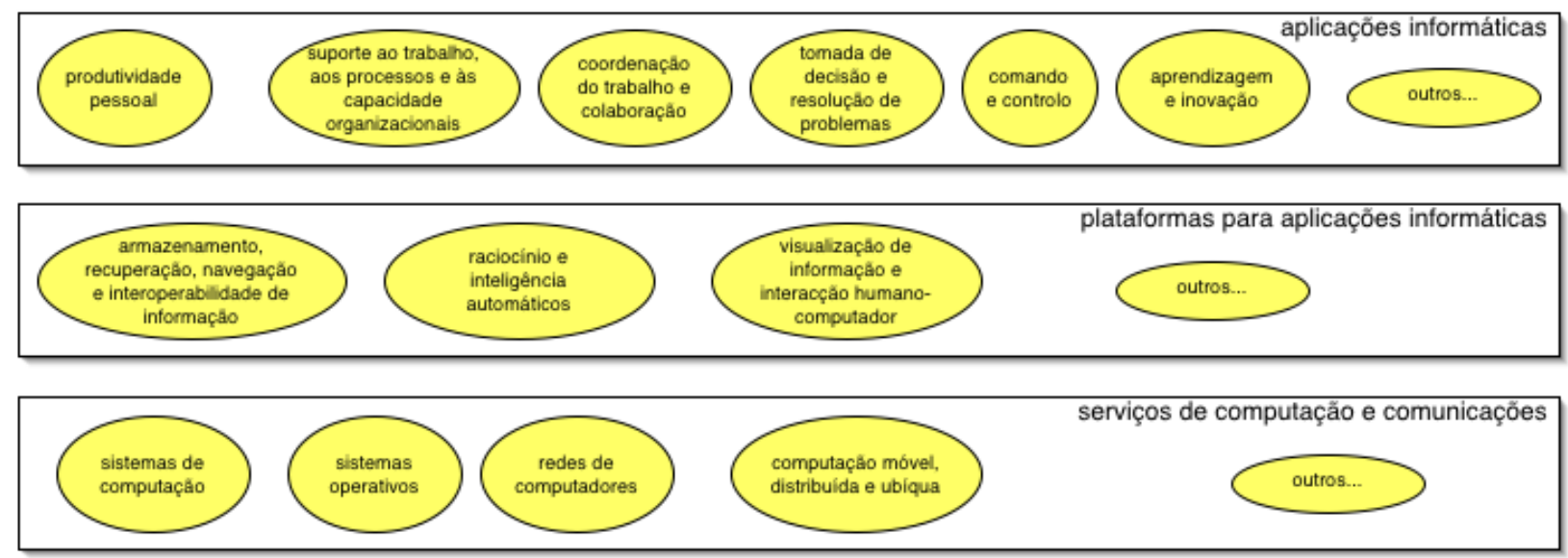

Figura 1 - Categorias de TI nas organizações.

Fonte: Autor. 


\section{ACTIVIDADES PROFISSIONAIS RELACIONADAS COM AS TI}

A perspectiva atrás apresentada, evidencia a omnipresença das TI na execução do trabalho organizacional e sugere uma intrincada relação das TI com pessoas, trabalho e estruturas organizacionais e sociais.

Uma consequência desta perspectiva traduz-se na necessidade de que praticamente qualquer pessoa na organização, independentemente da carreira profissional em que se enquadrada, possua competências básicas e uma cultura alargada sobre TI. Quer no que diz respeito ao modo como as TI podem constituir-se como amplificadoras das capacidades cognitivas quer no modo como as TI se aplicam às actividades típicas do trabalho que essa pessoa executa. A literacia digital é efectivamente um desafio da sociedade moderna, sendo a iliteracia digital um real obstáculo ao acesso ao mercado de trabalho. Esta iliteracia manifesta-se particularmente naqueles que não são nativos digitais, nos segmentos menos favorecidos das sociedades ditas desenvolvidas e nos países em vias de desenvolvimento.

As competências que correspondem a uma literacia digital básica, não esgotam obviamente as competências necessárias para garantir a disponibilidade e assegurar o bom funcionamento das TI e das suas aplicações nas organizações. Estes aspectos das modernas organizações exigem a participação de profissionais com competências científicas e tecnológicas que envolvem as TI.

Utilizando a classificação atrás apresentada (ver figura 1), será possível identificar as seguintes actividades relacionadas com o assegurar que a adopção e exploração das aplicações informáticas decorra de forma adequada:

i. Actividades relacionadas com a disponibilização de aplicações informáticas para suporte a situações de trabalho organizacional;

Inclui-se nesta categoria não só a obtenção, instalação, configuração de aplicações, mas também a condução de mudanças nas formas de trabalho por forma a enquadrar, de forma adequada, a utilização dos novos agentes informáticos de trabalho e a consequente divisão de trabalho entre agentes humanos e informáticos;

Estas actividades envolvem sobretudo conhecimento sobre as tecnologias das categorias a) e b) atrás apresentadas - aplicações informáticas e plataformas para aplicações informáticas;

ii. Actividades relacionadas com a construção de aplicações informáticas ou seja, a condução de projectos de engenharia de software que culminam com a disponibilização de uma aplicação informática pronta a ser instalada para posterior configuração e exploração;

A complexidade do software e da sua produção leva a que o desenvolvimento de aplicações informáticas deva ser encarado como uma actividade especializada que exige um conjunto vasto e específico de competências. Não é uma actividade ao alcance de qualquer organização, sobretudo no caso de organizações de pequena dimensão ${ }^{4}$. Não será, portanto expectável que a existência deste tipo de actividade na estrutura organizacional

\footnotetext{
${ }^{4}$ Hoje em dia, existe uma oferta alargada de aplicações informáticas capazes de lidar com as necessidades do trabalho organizacional. A maior parte destas necessidades poderá assim ser suprida no mercado global das TI. Deste modo, ao contrário do que acontecia há algumas décadas atrás, é comum que as organizações prefiram o recurso à aquisição de pacotes de software em detrimento do desenvolvimento de soluções à medida.

Enc. Bibli: R. Eletr. Bibliotecon. Ci. Inf., Florianópolis, n. esp., $2^{\circ}$ sem. 2010. ISSNe 1518-2924.
} 
seja regra ${ }^{5}$. Nas situações em que tal existe, fará sentido enquadrar esta actividade ao nível de actividades operacionais de suporte. Ou seja, actividades operacionais que não correspondem às actividades primárias da organização ${ }^{6}$. Estará assim a par de outras actividades operacionais de suporte como por exemplo: serviços jurídicos, oficinas de reparação e manutenção de equipamentos, etc.

s competências para a construção de aplicações informáticas envolvem as tecnologias das categorias a), b) e c) atrás apresentadas - aplicações informáticas, plataformas para aplicações informáticas e serviços de computação e comunicações;

iii. Actividades relacionadas com o estabelecimento e exploração dos serviços de computação e comunicações que permitam a execução das aplicações informáticas; A exploração deste serviços está associada a capacidades infra-estruturais que, tal como já anteriormente referido, é provável que, num futuro próprio, venham a ser generalizadamente assumidas como commodities e obtidas por contratualização a entidades externas às organizações;

Estas actividades envolvem principalmente a categoria c) de TI anteriormente apresentada - serviços de computação e comunicações - podendo ainda envolver algumas das plataformas da categoria acima b) - plataformas para aplicações informáticas;

Estas actividades vão aqui ser designadas por, respectivamente:

i) desenvolvimento de sistemas de informação - DSI,

ii) desenvolvimento de aplicações informática - DAI - e

iii) gestão de serviços de computação e comunicações - GSCC.

Considerando o que foi já dito sobre a distribuição do trabalho organizacional de natureza intelectual entre pessoas e TI, poderá ser estabelecido um paralelo entre o que nas organizações é feito relativamente à gestão das pessoas e o que é (deverá ser) feito relativamente à gestão das TI. Enquadram-se normalmente na função de gestão de recursos humanos actividades organizacionais relacionadas com: procura de pessoas com competências adequadas às necessidades da organização; contratação dessas pessoas; integração das pessoas na organização; disponibilização de oportunidades de formação e treino por forma a que as pessoas desenvolvam as suas competências ou adquiram novas competências; avaliação do desempenho das pessoas. No que diz respeito às TI fará sentido considerar aspectos tais como: estar atento ao aparecimento de novidades tecnológicas; procurar aplicações informáticas adequadas às necessidades e ambições da organização; planeamento de intervenções que procurarão tirar partido das TI; avaliação do desempenho das aplicações e do seu impacto na organização; gerir e controlar os riscos relacionados com a utilização das TI. Assim, justifica-se uma outra actividade organizacional relacionada com as TI e que corresponde à execução das actividades de gestão acima descritas:

iv) gestão das TI (ou gestão das TSI - GTSI).

A gestão das TSI não se limita, no entanto aos aspectos acima referidos, mais directamente relacionados com as TI. Enquadram-se também nesta função organizacional outras tarefas de gestão cujo foco é a informação e os recursos organizacionais envolvidos na disponibilização

\footnotetext{
${ }^{5}$ Organizações enquadradas na administração pública serão um caso particular na medida em que o carácter único destas instituições e a natureza da informação que manuseiam poderá justificar a existência interna de capacidades de desenvolvimento de aplicações informáticas.

${ }^{6}$ Exceptua-se obviamente a situação das empresas de produção de software (software house) em que a produção de software constitui precisamente a sua actividade primária.

Enc. Bibli: R. Eletr. Bibliotecon. Ci. Inf., Florianópolis, n. esp., $2^{\circ}$ sem. 2010. ISSNe 1518-2924.
} 
e exploração das TI, nomeadamente pessoas, finanças e a infra-estrutura da organização. Em termos gerais, a finalidade da gestão das TSI poderá ser apresentada como incluindo o assegurar de: eficiente utilização das TI na organização; adequada distribuição do trabalho organizacional entre pessoas e TI; existência de uma visão integrada e coerente da informação na organização; adequada utilização da informação na organização. A prossecução desta finalidade envolve tarefas tais como:

a) Criar e manter uma arquitectura da informação da organização - um mapa da estrutura da informação organizacional quer informação transaccional quer informação de gestão. A arquitectura da informação é normalmente cruzada com a arquitectura de processos $e$ actividades organizacionais (operacionais e de gestão) levando à identificação de clusters de actividades versus informação, permitido assim explicitar em que actividades organizacionais a informação é produzida, actualizada ou utilizada.

b) Criar e manter uma arquitectura das TI, incluindo aplicações e plataformas para aplicações, e seu cruzamento com as arquitecturas referidas no ponto anterior;

c) Planear intervenções de desenvolvimento organizacional focadas na adopção de TI (planeamento de SI);

d) Conduzir intervenções de desenvolvimento organizacional focadas na adopção TI;

e) Participar na contratualização da obtenção de aplicações informáticas ou de serviços informáticos;

f) Zelar pela segurança e privacidade da informação, planeando e executando as actividades necessárias para garantir tal segurança;

Uma parte das tarefas incluídas na GTSI, nomeadamente as relacionadas com a criação e manutenção das arquitecturas organizacionais e com o planeamento de intervenções organizacionais, podem ser vistas como fazendo parte do planeamento de SI (PSI) que pode assim ser apresentado como a principal componente da GTSI $^{7}$.

Destas quatro actividades - DSI, DAI, GSCC e GTSI - duas delas correspondem a responsabilidades nucleares dos profissionais de TSI, nomeadamente o DSI - desenvolvimento de sistemas de informação - e a GTSI - gestão das TSI. São actividades que estão indissociavelmente relacionadas com o negócio, a organização e os aspectos humanos e sociais que lhe estão associados. As outras duas, GSCC - gestão de serviços de computação e comunicações e DAI - desenvolvimento de aplicações informáticas, embora envolvam também conhecimentos sobre organização e gestão, ficam já fora da esfera mais restrita das responsabilidades dos profissionais de TSI. A primeira, tal como o nome sugere, tem a ver com a gestão de serviços. A segunda tem o seu espaço próprio normalmente designado por engenharia de software apesar de envolver uma forte interligação com o DSI desenvolvimento de sistemas de informação. Haverá situações em que um projecto de DSI engloba um sub-projecto de DAI, nomeadamente nos casos em que a opção escolhida para a disponibilização das aplicações informáticas passa pelo desenvolvimento à medida ${ }^{8}$.

\footnotetext{
${ }^{7}$ Num artigo de 1993, Carvalho e Amaral (CARVALHO, J. Á.; AMARAL, L. Matriz de actividades: um enquadramento conceptual para as actividades de planeamento e desenvolvimento de sistemas de informação. Sistemas de Informação, n. 1, 1993, p 37-48) apresentam estas actividades de modo diferente. A gestão de SI (GSI) é apresentada como incluindo o planeamento de SI (PSI) e o desenvolvimento de SI (DSI). Neste artigo irá ser adoptada a designação de "engenharia e gestão de SI" (EGSI) para referir, na generalidade, as actividades dos profissionais de TSI.

${ }^{8}$ A fase do processo de DAI normalmente designada por engenharia de requisitos envolve também, normalmente, competências relacionadas com a compreensão do trabalho organizacional.

Enc. Bibli: R. Eletr. Bibliotecon. Ci. Inf., Florianópolis, n. esp., $2^{\circ}$ sem. 2010. ISSNe 1518-2924.
} 
Para além daquelas duas actividades nucleares da área de TSI, DSI - desenvolvimento de sistemas de informação e GTSI - gestão das TSI, os profissionais de TSI têm vindo a ser chamados a participar, ou até a conduzir, outras actividades organizacionais em que as TI são elemento de grande importância, nomeadamente:

1) engenharia do trabalho dos processos e das organizações (ETPO) e;

2) gestão do conhecimento organizacional (GCO).

A ETPO - engenharia do trabalho dos processos e das organizações é uma actividade muito próxima do que normalmente se designa por design organizacional. Visa o definir de estruturas de trabalho a vários níveis de foco: a um nível mais elementar que poderá ser designado por situações de trabalho; ao nível de processos organizacionais, envolvendo, portanto uma perspectiva transversal de articulação do trabalho nas organizações; e finalmente ao nível global das organizações, focando inclusivamente na distribuição de responsabilidades por várias unidades organizacionais ${ }^{9}$. O envolvimento de profissionais com competências em TI na engenharia do trabalho dos processos e das organizações resulta do facto de a execução do trabalho organizacional, nomeadamente o trabalho de natureza intelectual, ser assegurada por pessoas e por aplicações das TI. O design de estruturas de trabalho carece, pois de conhecimentos sobre as TI e suas aplicações e potencial de utilização nas organizações.

A GCO - gestão do conhecimento organizacional abrange um conjunto de preocupações relacionadas a acuidade das funções da inteligência organizacional - percepção, atenção, memória, produção de pensamentos, raciocínio, conhecimento, utilização da linguagem, aprendizagem, imaginação e inovação. Também neste caso a necessidade de competências em TI resulta do facto de estas funções serem asseguradas por pessoas e por aplicações das TI. Note-se que só faz sentido considerar esta actividade em organizações onde as TI são já usadas extensivamente, especialmente na viabilização da partilha de informação e na mediação da comunicação organizacional.

\section{ACTIVIDADES TSI E OUTRAS ACTIVIDADES ORGANIZACIONAIS}

Uma das particularidades dos profissionais de TSI é que as suas actividades envolvem uma forte interacção com outras actividades organizacionais. A inevitabilidade de lidar com informação em qualquer forma de trabalho organizacional - sejam enquadrado em actividades nucleares, de suporte ou de gestão - e a corrente omnipresença das TI, levam a que isso aconteça.

No sentido de chamar a atenção para a diversidade de áreas organizacionais com que os profissionais de TSI têm que lidar, apresentam-se de seguida algumas funções organizacionais sendo feita referência às suas associações as TI.

\subsection{Actividades nucleares}

O impacto das TI nas actividades nucleares de uma organização atinge o seu máximo quando estão em causa negócios viabilizados pelas próprias TI, nomeadamente aqueles em que o objecto do negócio é informação - os serviços de informação. No entanto, em qualquer outro

\footnotetext{
${ }^{9}$ Uma outra actividade organizacional relacionada com a sistematização do trabalho organizacional e com a definição de padrões de desempenho é a gestão da qualidade. Embora assumindo normalmente uma perspectiva diferente, poderá considerar-se incluída na ETPO. Enc. Bibli: R. Eletr. Bibliotecon. Ci. Inf., Florianópolis, n. esp., $2^{\circ}$ sem. 2010. ISSNe 1518-2924.
} 
negócio, as TI têm tido impacto relevante nas actividades nucleares das organizações. Nos parágrafos seguintes apresentam-se actividades, algumas das quais integram a cadeia de valor tal como proposta por Porter (1985), onde tal impacto é particularmente importante.

Marketing e vendas - o conjunto de tecnologias que viabiliza o que normalmente se designa por comércio electrónico corresponde talvez à principal influência das TI nas organizações. $\mathrm{O}$ comércio electrónico corresponde a um canal de marketing e vendas adequado à actual sociedade globalizada. Por outro lado, o histórico das vendas de uma organização (correspondendo aos registos acumulados ao longo dos anos) passou a ser explorado automaticamente, com tecnologias tais como o data mining, à procura de padrões nos comportamentos de compra dos clientes o que levou ao emergir de novas práticas e funções organizacionais viabilizadas pelas TI, tal como a gestão do relacionamento com os clientes (customer relationship management - CRM).

Centro de contactos (contact center) - as TI baseadas em computador que lidam com informação digitalizada permitiram a centralização dos contactos de uma organização, permitindo juntar num mesmo posto de trabalho contactos recebidos por diferentes canais, tais como telefone, fax, correio electrónico ou carta postal. Foram assim viabilizadas práticas organizacionais que garantem atendimento mais eficiente e tratamento personalizado dos clientes e reforçam a possibilidade de gerir o relacionamento com os clientes.

Logística - também a nível da logística, quer de entrada quer de saída, as TI trouxeram profundas mudanças. As modernas práticas de logística - por exemplo o que se designa normalmente por supply chain management (SCM) - assentam numa sofisticada utilização da TI que envolve a interligação de repositórios de informação de clientes, fornecedores e transportadores de bens, bem como interoperabilidade entre as respectivas plataformas informáticas.

\subsection{Actividades de suporte}

Por actividades de suporte deverão entender-se as actividades organizacionais necessárias ao regular funcionamento da empresa (as actividades nucleares), mas que não têm a ver com a sua finalidade nem com as actividades relacionadas com direcção ou coordenação (as actividades de gestão). De entre as actividades de suporte destacam-se:

Comunicação interna - O correio electrónico tem vindo a tornar-se o meio mais frequente de comunicação nas organizações, servindo para, sobretudo de forma assíncrona, estabelecer canais de comunicação de 1 para 1 ou de 1 para muitos. Em complemento com o correio electrónico, outras formas de comunicação mediada por TI têm vindo a aparecer nas organizações e a mudar o modo de comunicar internamente, quer a nível da comunicação formal quer a nível da comunicação informal.

Arquivo - Desde há já muito tempo que muitas organizações optavam por arquivar os seus documentos em suportes que exigem menos espaço que o suporte original - o papel. Com a possibilidade de digitalização dos documentos, aquela tendência naturalmente aumentou. Acresce que cada vez mais os documentos chegam já em versão digital ou então são digitalizados logo na altura em que são recebidos. Assim, a colocação de documentos em arquivo nem chega a precisar de mudança de suporte. 
Segurança - A segurança das organizações conhece hoje em dias novas vulnerabilidades organizacionais e ameaças: intrusões, roubos de informação, ataques às plataformas informáticas da organização. Com a agravante de que os perpetradores destes ataques e roubos poderem estar à distância e apenas detectáveis através de constante vigilância no ambiente informática da organização. A segurança informática é, hoje em dia, uma vertente da segurança das organizações que carece de crescente atenção.

\subsection{Actividades de gestão}

A nível das actividades de gestão destaca-se o envolvimento de profissionais de TSI nas seguintes actividades:

Planeamento estratégico - $\mathrm{O}$ estabelecimento de objectivos e metas a alcançar bem como as estratégias a seguir para os atingir deverá considerar por um lado as competências humanas existentes e necessárias e, por outro lado, o que as TI permitem fazer. Quer as aplicações das TI já existentes nas organizações quer outras passíveis de serem obtidas e disponibilizadas.

Vigilância competitiva (competitive intelligence) - A recolha de informação sobre mercados, competidores e outros elementos do ambiente bem como o tratamento de tal informação no sentido de identificar tendências e outros padrões depende cada vez mais das TI.

Auditoria - Considerando que cada vez mais os registos organizacionais são suportados por TI, o exercício de funções de auditoria carece de competências de TI por forma a garantir a capacidade de verificar a autenticidade e validade desses registos.

Controlo - o fornecimento de informação para gestão, tipicamente no sentido de controlo, esteve na origem do emergir do interesse pela utilização dos computadores nas organizações os sistemas de informação para gestão (management information systems). Desenvolvimentos tecnológicos recentes - incluindo data warehousing, OLAP (on-line analytical processing), sistemas de informação para executivos (executive information systems) - dotaram os gestores de instrumentos de trabalho que, literalmente, lhes permite navegar na informação sobre o estado da organização.

Prestação de contas aos stakeholders (públicos ou privados) - A disponibilização de informação que permita a todos os interessados acompanhar a evolução do desempenho das organizações é hoje em dia, e graças às TI, possível de realizar de forma bem mais frequente do que o que era possível através de relatórios de actividades e de contas tipicamente actuais.

Coordenação - a coordenação de recursos - humanos, financeiros, equipamentos, infraestruturas - carece da existência de registos actualizados das existências e das utilizações dos recursos. Grandes progressos foram feitos nos últimos anos neste aspecto. Os pacotes de software normalmente designados por ERP ${ }^{10}$ - enterprise resource planning - têm vindo a permitir uma visão integrada da utilização dos recursos, eliminando múltiplos registos de existências e de consumos e viabilizando uma melhor coordenação dos recursos

\footnotetext{
${ }^{10}$ As aplicações ERP não visam exclusivamente a coordenação. Estão intrinsecamente relacionadas com as actividades nucleares, dando suporte ao processamento das transacções organizacionais e simultaneamente permitem a criação e actualização dos registos relacionados com os recursos envolvidos.

Enc. Bibli: R. Eletr. Bibliotecon. Ci. Inf., Florianópolis, n. esp., $2^{\circ}$ sem. 2010. ISSNe 1518-2924.
} 
organizacionais. Por outro lado, sistemas de apoio à decisão adequados à gestão de cada um dos diferentes tipos de recursos têm também contribuído para uma maior capacidade de gestão e uma maior eficiência na organização.

\section{COMPETÊNCIAS NUCLEARES DOS PROFISSIONAIS DE TSI}

Será interessante comparar as actividades profissionais de TSI atrás apresentadas com as competências de mais alto nível (high-level capabilities), correspondendo aos principais resultados de aprendizagem na formação inicial (undergraduate) em TSI, apresentadas num recente estudo promovido pela AIS (TOPI et al., 2010). Neste estudo foram identificadas sete competências nucleares (ver tabela 1) que correspondem em grande parte ao que foi descrito como sendo as principais actividades dos profissionais de TSI:

\begin{tabular}{|c|c|c|}
\hline \multicolumn{2}{|c|}{$\begin{array}{l}\text { Competências nucleares da } \\
\text { proposta da AIS para o } \\
\text { currículo de formação inicial } \\
\text { em TSI }\end{array}$} & \multirow{2}{*}{$\begin{array}{l}\text { Actividades profissionais em TSI tal como apresentadas na secção } 5 \\
\begin{array}{l}\text { Corresponde directamente à actividade de ETPO, sendo no entanto } \\
\text { razoável associá-la também ao DSI. }\end{array}\end{array}$} \\
\hline AIS 1 & $\begin{array}{l}\text { Melhoria de processos } \\
\text { organizacionais }\end{array}$ & \\
\hline AIS 2 & $\begin{array}{l}\text { Exploração de } \\
\text { oportunidades criadas } \\
\text { por inovações } \\
\text { tecnológicas }\end{array}$ & $\begin{array}{l}\text { Esta competência é transversal a todas as actividades profissionais de TSI } \\
\text { apresentadas. }\end{array}$ \\
\hline AIS 3 & $\begin{array}{l}\text { Compreender e dar } \\
\text { satisfação a requisitos } \\
\text { informacionais }\end{array}$ & $\begin{array}{l}\text { Esta competência está claramente associada a DSI. No entanto, é possível } \\
\text { associá-la também ao DAI. Aliás, no estudo da AIS é apresentada nesse } \\
\text { sentido. }\end{array}$ \\
\hline AIS 4 & $\begin{array}{l}\text { Conceber e gerir a } \\
\text { arquitectura } \\
\text { organizacional }\end{array}$ & $\begin{array}{l}\text { Lidar com a arquitectura organizacional é uma competência essencial a } \\
\text { nível da GTSI. É também necessária quando a actividade de ETPO é } \\
\text { conduzida ao nível mais elevado, i.e., ao nível da organização. }\end{array}$ \\
\hline AIS 5 & $\begin{array}{l}\text { Identificar e avaliar } \\
\text { soluções alternativas e } \\
\text { formas de as obter }\end{array}$ & $\begin{array}{l}\text { Esta competência pode ser entendida a dois níveis: } \\
\text { 1) como obter soluções específicas no contexto do DSI; } \\
\text { 2) decidir relativamente a opções de fundo a nível global da organização; } \\
\text { por exemplo, optar pelo desenvolvimento interno de aplicações em } \\
\text { alternativa à aquisição de pacotes ou contratualização de software houses; } \\
\text { ou criar e manter uma infra-estrutura para a exploração das aplicações em } \\
\text { detrimento da contratação de serviços externos de alojamento (hosting) de } \\
\text { aplicações; neste segundo sentido, a competência poderá corresponder à } \\
\text { actividade de GTSI. }\end{array}$ \\
\hline AIS 6 & $\begin{array}{l}\text { Assegurar a segurança } \\
\text { da informação e de } \\
\text { infra-estrutura de } \\
\text { suporte }\end{array}$ & $\begin{array}{l}\text { Pelo menos ao nível mais geral (definição de estratégia e políticas) esta } \\
\text { competência enquadra-se na GTSI e na sua relação com as actividades } \\
\text { organizacionais associadas ao zelar pela segurança da organização. }\end{array}$ \\
\hline AIS 7 & $\begin{array}{l}\text { Compreender, gerir e } \\
\text { controlar os riscos } \\
\text { associados às TI }\end{array}$ & Corresponde a responsabilidades da GTSI. \\
\hline
\end{tabular}

Das várias actividades atrás identificadas, há uma que parece estar ausente do estudo da AIS a gestão do conhecimento organizacional (GCO). Não necessariamente por ser excluída das responsabilidades dos profissionais de TSI, mas provavelmente por ser entendida como uma actividade mais complexa que não fará sentido abordar ao nível de formação inicial. Note-se 
que a proposta da AIS para o curriculum em TSI ao nível de mestrado, publicada por Gorgone et al. (2006), considera já a gestão do conhecimento como uma actividade profissional emergente.

\section{ENGENHARIA E GESTÃO DE TSI}

As actividades profissionais de TSI acima descritas partilham algumas características comuns, nomeadamente:

1) implicam lidar com questões tecnológicas com consciência plena do contexto organizacional, humano e social que enquadra a adopção, utilização e aproveitamento das TI;

2) envolvem lidar com fenómenos/objectos de elevada complexidade;

3) exigem também elevado nível de competência técnico-científica e capacidade de aplicar abordagens rigorosas e sistemáticas fundamentadas em conhecimento sobre os fenómenos organizacionais, humanos e sociais relevantes.

No entanto, enquanto umas implicam acções de intervenção, conduzidas em ambiente de projecto - típicas das profissões da engenharia - outras desenrolam-se na lógica de acompanhamento contínuo de algum objecto de atenção - característica das actividades de gestão. Assim, os profissionais de TSI poderão ser apresentados como engenheiros e gestores de TSI, termos estes associados a profissões que possuem as características acima referidas. Também ambas as profissões se enquadram na categoria de profissões que envolvem design, no sentido definido por Simon (1981, p. 129) - "[...] devis[ing] courses of action aimed at changing existing situations into preferred ones.".

A engenharia e gestão de TSI pode ser considerada uma profissão em consolidação, resultante da combinação e evolução de outros perfis profissionais, nomeadamente:

1) Engenharia informática orientada para o desenvolvimento de aplicações informáticas de suporte ao trabalho organizacional;

2) Gestão de recursos;

3) Gestão da informação;

4) Design organizacional.

Considerando a necessidade de combinação de competências das TI com competências das ciências económicas e empresariais, não é de estranhar que a formação de profissionais de TSI possa ser encontrada em instituições de ensino superior associadas não só a escolas de engenharia e tecnologia mas também a escolas de gestão e de negócios. Tal acontece em vários países no mundo incluindo Portugal.

Pelas mesmas razões, as actividades centrais ao engenheiro e gestor TSI aparecem enquadradas em associações profissionais com origem, quer em profissões mais próximas da computação e das tecnologias da informação, quer profissões mais próximas da gestão. Exemplos de tais associações incluem: British Computer Society (BCS) - no Reino Unido; Association for Information Technology Professionals (AITP, anteriormente Data Processing Management Association - DPMA) nos Estados Unidos da América; Association for Computing Machinery (ACM) nos Estados Unidos da América; Institute of Electrical and Electronic Engineers - Computer Society (IEEE) nos Estados Unidos da América, e 
Information Management and Operations Research (INFORMS), também nos Estados Unidos da América.

Em Portugal, a Ordem dos Engenheiros, no seu papel de enquadramento dos profissionais de engenharia, considera a existência de engenheiros cujo principal objecto de intervenção é as tecnologias da informação - o Colégio de Engenharia Informática. E entre os domínios de intervenção da Engenharia Informática considera os Sistemas de Informação Organizacionais. No contexto da ordem dos engenheiros será razoável apresentar o perfil profissional de engenharia e gestão de TSI como correspondendo ao perfil de um Engenheiro Informático, cujo domínio de intervenção é precisamente o dos sistemas de informação organizacionais. A inclusão do termo "gestor" na designação do perfil sugere o envolvimento destes profissionais em actividades que não são de projecto, envolvendo antes um acompanhamento contínuo de situações organizacionais. Tal componente é compatível com o perfil de engenharia, existindo exemplos de combinação destes dois perfis noutras áreas (p. ex., engenharia e gestão industrial).

A utilização do termo "engenharia" carece, no entanto de alguma clarificação. Num sentido mais restrito do termo, engenharia está associada à aplicação de conhecimento relacionado com fenómenos da natureza - sistematizados em ciências como a física, a química ou a biologia - em actividades de resolução de problemas e de criação de artefactos para os quais tais fenómenos são particularmente relevantes. Aspectos humanos e sociais são considerados essencialmente para a definição do modo de interacção entre humanos e artefactos ou para a definição de critérios de sucesso e medidas do impacto das soluções encontradas e dos artefactos criados.

No caso da área de TSI os fenómenos que estão na essência das actividades de intervenção são de natureza humana e social. Estão relacionados com as capacidades cognitivas humanas e ocorrem no contexto de situações de comunicação associadas a manifestações humanas e sociais tais como: interacção (entre pessoas, e, através destas, com e entre organizações); cooperação (entre pessoas e, através destas, entre organizações); coordenação do trabalho; aprendizagem colectiva; vigilância competitiva, definição de intenções; definição de estratégias; monitorização de estados; controlo. O conhecimento relevante para as actividades de engenharia e gestão de TSI envolve, pois ciências relacionadas com aspectos tão distintos como linguagem, cognição, aprendizagem, comunicação, comportamentos humanos e sociais, nomeadamente no contexto das organizações.

Assim, é necessária uma acepção mais lata do termo "engenharia" para legitimar a sua aplicação na caracterização dos profissionais de TSI, que esteja ancorada sobretudo nas características do trabalho realizado. Em tal perspectiva, a complexidade das técnicas e métodos disponíveis para a condução das actividades de intervenção em sistemas de informação (o que faz com que a sua aplicação não seja óbvia, mas exija a utilização de procedimentos analíticos sofisticados) exibe características típicas das actividades de engenharia. Também o intervir em sistemas de informação se enquadra perfeitamente no esforço realizado pelo Homem no sentido de melhorar as suas condições de vida - uma possível definição de engenharia. Neste caso, o objecto do melhoramento é um sistema de informação ou, de uma forma ainda mais abrangente, os processos que envolvem informação numa organização. Finalmente, a definição de "engineering design" apresentada por Wallace (WALLACE, 1981) - como sendo o uso de princípios e conhecimento científico, imaginação e julgamento na definição de estruturas, máquinas, dispositivos e sistemas que desempenhem Enc. Bibli: R. Eletr. Bibliotecon. Ci. Inf., Florianópolis, n. esp., 2º sem. 2010. ISSNe 1518-2924. 
determinadas funções com um máximo de economia e eficácia - ajusta-se perfeitamente àquelas actividades de intervenção organizacional envolvendo tecnologias e sistemas de informação.

Não se pretende sugerir que todos os profissionais de TSI deverão estar aptos a assumir responsabilidades em todo o espectro de actividades profissionais da área. Com certeza que, ao longo da carreira, cada profissional seguirá um percurso de especialização que o tornará particularmente especializado em algumas das actividades da engenharia ou gestão de TSI, ou ainda especializado na execução de alguma actividade profissional nalgum aspecto organizacional em particular. Este último tipo de especialização indicia que as profissões de TSI podem também ser conduzidas em contextos de consultoria, aplicadas em diferentes organizações.

Possíveis cenários de evolução dos perfis profissionais de TSI foram já alvo de discussão na literatura da área, pelo menos desde os anos 1990 (p. ex., KEEN, 1991, EARL; SKYRME, 1992 e AMARAL, 1994). Keen (1991), por exemplo, define dois perfis de profissionais híbridos, combinando competências TI e de gestão. A figura 2 ilustra quatro perfis profissionais propostos por Keen num espectro que vai desde o puramente TI ao gestor "puro". Os perfis intermédios correspondem a perfis TSI, designados por Keen por "híbridos": TSI 1 - apoio ao desenvolvimento (development support), híbrido com formação predominantemente em TI; TSI 2 - apoio ao negócio (business support), híbrido com formação predominante em gestão.

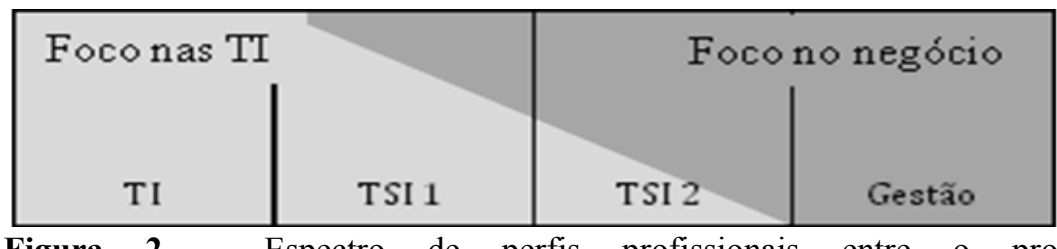

Figura 2 - Espectro de perfis profissionais entre o profissional de TI e o gestor; destaque para os dois perfis TSI: apoio ao desenvolvimento e apoio ao negócio.

Fonte: Autor.

\section{CORPO DE CONHECIMENTO DA ÁREA CIENTÍFICA DE TSI}

As actividades profissionais de TSI foram, no início deste artigo, consideradas como constituindo critério apropriado para definir o âmbito da área científica de TSI. Procura-se em particular identificar os grandes grupos do corpo de conhecimento associado à área. Neste corpo de conhecimento irão ser considerados os seguintes grupos: i) fenómenos cuja compreensão e explicação é relevante para a área; ii) métodos, técnicas e ferramentas da profissão; iii) as TI em si mesmas; iv) abordagens gerais à resolução de problemas e à forma de pensar.

\subsection{Os fenómenos das TSI}

Relembra-se que as actividades profissionais de TSI procuram contribuir para que as organizações tirem proveito das TI para melhorarem o seu funcionamento. Assim, os principais fenómenos cuja compreensão é importante para os profissionais de TSI abrangem as situações organizacionais que são objecto de intervenção, a dinâmica da mudança em contexto organizacional (ou da sociedade) e ainda as próprias acções dos profissionais de TSI. 
Começando pelas situações que são objecto de intervenção pelos profissionais de TSI, temos em primeiro lugar os fenómenos relacionados com a utilização da informação e, em particular, os fenómenos em que a informação é suportada por TI. Estes fenómenos são de natureza humana e social. Estão relacionados com as capacidades cognitivas humanas, a linguagem, a aprendizagem, a comunicação, a cooperação, mas também com a acção humana, nomeadamente acções a nível intelectual. De entre estas salienta-se a tomada de decisões, pelo importante papel que assume na gestão das organizações. Aquelas intervenções ocorrem tipicamente no contexto das organizações e afectam a estrutura do trabalho e das organizações. Relevam assim um conjunto de fenómenos de natureza social que correspondem ao modo como as entidades que executam trabalho se organizam por forma a serem eficientes no cumprimento da sua finalidade.

Note-se que estes fenómenos são também objecto de estudo em outras áreas, tais como ciências cognitivas, ciências da linguagem, psicologia, ciência da informação, ciências organizacionais, cibernética ou comportamento organizacional. O envolvimento de TI, se considerado, será um factor adicional num estudo. O conhecimento resultante será focado nos aspectos específicos de relevância para a respectiva área científica e apresentada em tal contexto.

Em segundo lugar temos os fenómenos associados à estruturação de situações de trabalho e à dinâmica da mudança destas situações. Desde o nível do posto de trabalho individual, a situações mais abrangentes tais como os processos organizacionais ou ainda a estrutura global da organização. Estruturação do trabalho e dos recursos, reacção à mudança, aceitação de tecnologia, cultura organizacional, inovação, difusão de tecnologia são exemplos de aspectos relevantes associados a este conjunto de fenómenos. Também estes fenómenos são relevantes para outras áreas científicas tais como psicologia, sociologia, comportamento organizacional, economia.

O terceiro conjunto de situações que importa compreender são as próprias actividades dos profissionais - os processos de gestão e de intervenção que conduzem no âmbito do seu trabalho profissional. Neste caso a compreensão traduz-se normalmente em descrições e explicações dos factores que contribuem para o sucesso e insucesso das actividades de gestão e de intervenção.

\subsection{Métodos, técnicas e ferramentas da profissão}

O corpo de conhecimento da área científica de TSI inclui um conjunto de métodos, técnicas e ferramentas usadas pelos profissionais de TSI no seu trabalho. Métodos técnicas e ferramentas que os ajudam a representar os problemas que enfrentam e as soluções que propõem ou que suportam os raciocínios inerentes ao seu trabalho. A eficácia destes métodos, técnicas e ferramentas depende obviamente da compreensão existente sobre o seu trabalho e sobre os objectos da intervenção. Exemplos de tais métodos, técnicas e ferramentas incluem:

1) modelos conceptuais e técnicas para organização da informação e do trabalho organizacional, para diagnóstico de situações de trabalho, processos e organizações;

2) modelos de processo para as actividades de intervenção;

3) linguagens para a representação da estrutura da informação, da estrutura de situações de trabalho; 


\section{$9.3 \mathrm{TI}$}

Relativamente às TI, é incontornável que os profissionais conheçam bem a tecnologia com que lidam e que procuram que as organizações utilizem da melhor maneira. Há no entanto que ajustar tal conhecimento à missão dos profissionais de TSI, diferenciando-o do conhecimento necessário a outros especialistas em TI cuja principal responsabilidade é a construção de artefactos e dispositivos informáticos.

\subsection{Abordagens à resolução de problemas}

Neste grupo enquadra-se conhecimento, de natureza geral. Geral porque dado o seu nível de abstracção é aplicável a um alargado conjunto de situações. Refira-se em primeiro lugar a matemática enquanto linguagem com capacidade de representar e operar sobre modelos diversos suportando raciocínios rigorosos.

Por outro lado, a complexidade dos fenómenos em causa e a necessidade de abordagens abrangentes dos múltiplos factores relevantes para tais fenómenos tem levado à adopção de abordagens sistémicas para representar os objectos de trabalho e para sustentar os raciocínios de conceptualização e de design inerentes às actividades do engenheiro e gestor de sistemas de informação. Assim, ciências dos sistemas e formas de raciocínio sistémico integram também o corpo de conhecimento dos engenheiros e gestores de TSI.

\subsection{Integração de conhecimento}

A figura 3 procura ilustrar o modo como os vários grupos de conhecimento acima referidos se articulam e resultam num corpo de conhecimento que permite aos engenheiros e gestores de TSI conduzirem as suas actividades profissionais com sustentação científica.

A figura procura ainda sugerir que muitos dos elementos deste corpo de conhecimento não são exclusivos da área científica de TSI. Eles integram também o corpo de conhecimento de outras áreas científicas que partilham com a área de TSI alguns dos objectos de foco e interesse. Salienta-se a multidisciplinaridade do trabalho dos profissionais de TSI na medida em que envolve conhecimento produzido em várias disciplinas (áreas científicas) com objectos de interesse significativamente diferentes e com métodos de I\&D também razoavelmente diferentes. 


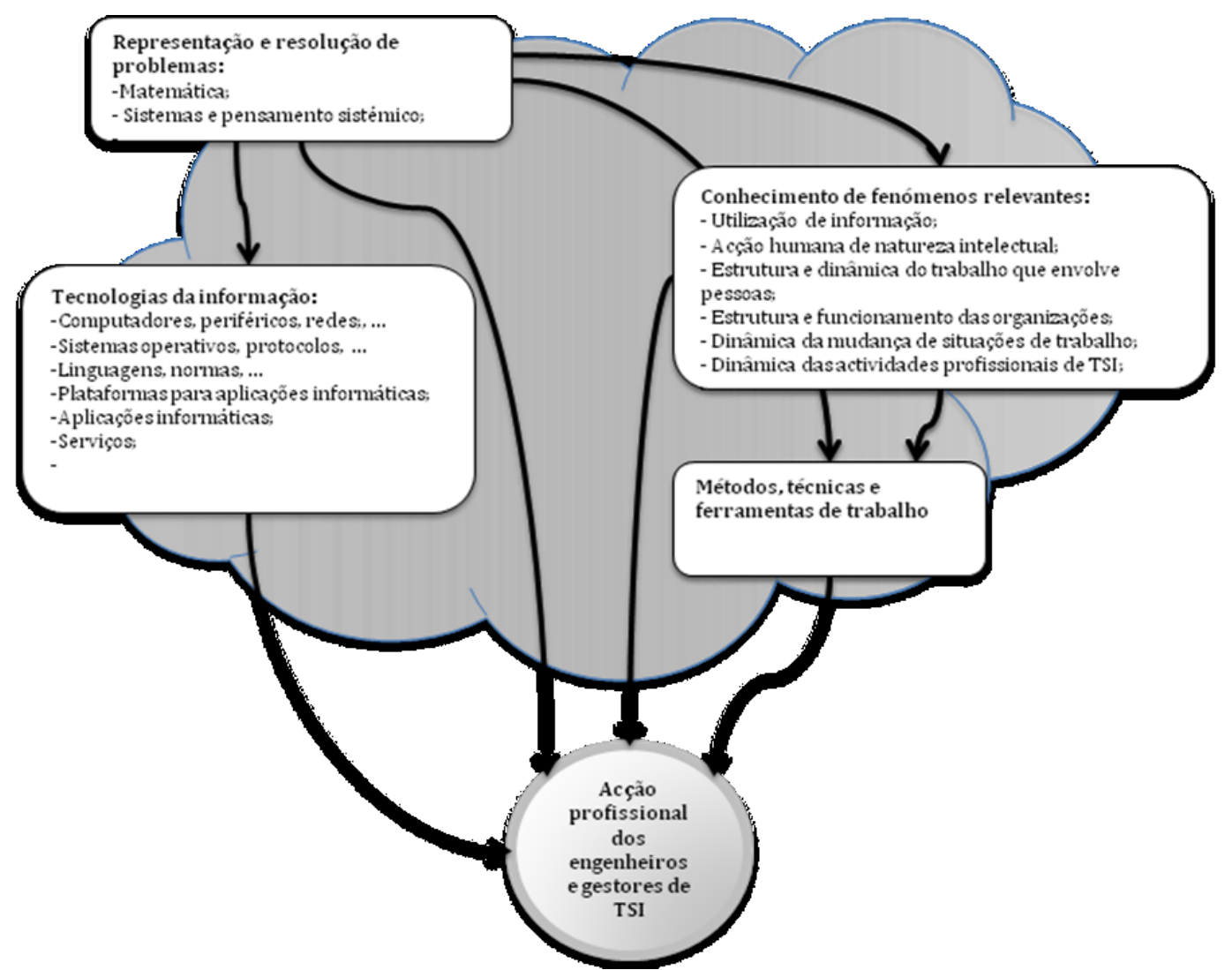

Figura 3 - Articulação dos vários grupos do corpo de conhecimento da área científica de TSI.

Fontes: Autor

\section{MÉTODOS DE I\&D PARA DESENVOLVIMENTO DO CORPO DE CONHECIMENTO}

O elemento da caracterização da área científica de TSI que falta abordar é o dos métodos de I\&D usados por aqueles que contribuem para o alargar o corpo de conhecimento da área. Normalmente, numa determinada área científica, no processo de criação de novo conhecimento, é usado um número restrito de métodos de I\&D. No entanto, a multidisciplinaridade inerente à área de TSI tem como consequência a necessidade de recorrer a uma diversidade de métodos de I\&D.

Na tabela 2 é apresentado um resumos do espectro de métodos de I\&D usados na área para validação empírica dos contributos para o seu corpo de conhecimento. A tabela está organizada em duas dimensões. Uma dimensão corresponde à finalidade da actividade de I\&D: compreender ou explicar fenómenos relevantes para a área ou criar nova tecnologia, sejam métodos, técnicas, ferramentas, artefactos. A outra dimensão corresponde ao ambiente em que o processo de I\&D é conduzido: no laboratório ou no campo, i.e., fora do laboratório. 


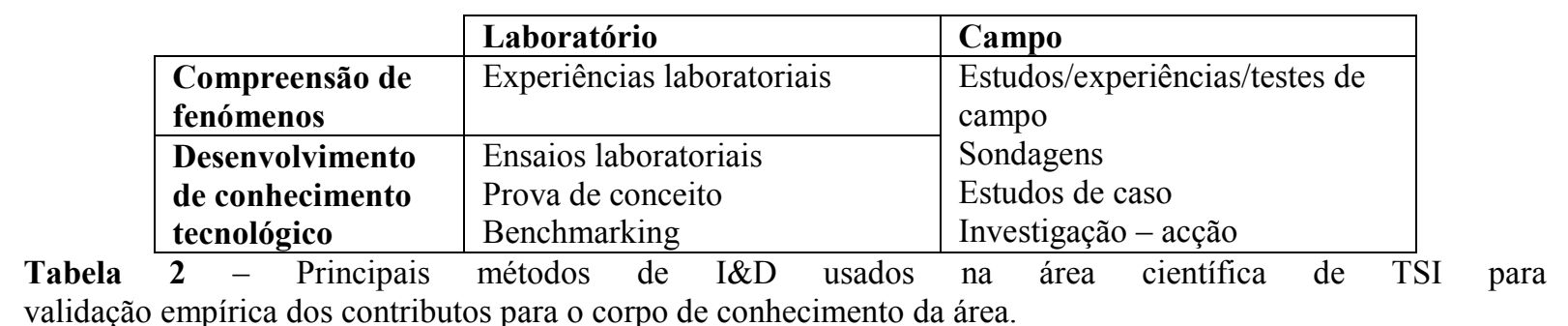

rica dos contributos para o corpo de conhecimento da área.

Fonte: autor

Trabalhar em laboratório significa trabalhar em condições com elevado nível de controlo, ou seja, todos os factores considerados relevantes para o fenómeno em causa estarão, de alguma forma controlados. As correspondentes variáveis são monitorizadas e será possível alterar o seu valor por forma a perceber o efeito dessa alteração nas varáveis dependentes. Resultados obtidos em estudos laboratoriais têm um potencial de generalização que está fora do alcance dos estudos de campo mas são afectados pela artificialidade do próprio ambiente do estudo, introduzindo assim limitações que reflectem a ausência das inevitáveis ocorrências imprevisíveis de um ambiente real.

No caso dos métodos laboratoriais é feita uma distinção entre experiências laboratoriais e ensaios laboratoriais. Embora na sua essência não sejam significativamente diferentes, a designação ensaio laboratorial é tipicamente usada para designar as situações em que é testada a eficácia de elementos tecnológicos, sejam artefactos ou processos.

$\mathrm{Na}$ área de TSI, a utilização de experiências laboratoriais para a compreensão de fenómenos restringe-se a situações em que a unidade de análise é o indivíduo (decisor, gestor, trabalhador) ou o grupo (grupo de decisores, gestores, pessoas envolvidas em situação de trabalho bem delimitada). Correspondem a ambientes de investigação comuns na psicologia e ciências cognitivas. No entanto, a maior parte dos fenómenos relevantes da área das TSI, pelo facto de envolverem factores organizacionais, dificilmente são transponíveis para um ambiente laboratorial. Daí que na área predominem os estudos conduzidos em campo.

Quanto aos métodos laboratoriais associados ao desenvolvimento de conhecimento tecnológico, correspondem a situações típicas de construção e teste de ferramentas e artefactos. Para além dos já referidos ensaios laboratoriais, equivalentes às experiências laboratoriais usadas no estudos que levam à compreensão de fenómenos, são referidos os estudos de prova de conceito e de benchmarking.

A prova de conceito corresponde a uma situação em que a eficácia da tecnologia criada é demonstrada num ambiente artificial e normalmente com condições favoráveis. O que está em causa é demonstrar a eficácia da nova tecnologia. Resolver problemas relacionados com a sua aplicação em situações mais adversas será já visto como a introdução de melhorias naquilo que é essencial. Será assim legítimo fazer a demonstração num cenário favorável. A situação criada para efectuar esta demonstração poderá ser designada por "caso demonstração" ou "caso exemplo"11.

O benchmarking corresponde a uma forma de testar tecnologia que envolve a comparação da nova tecnologia proposta com outras tecnologias alternativas. É uma forma de ensaio laboratorial em que os vários artefactos em causa são ensaiados em condições idênticas. Este

\footnotetext{
${ }^{11}$ Sobretudo em publicações da área da informática (computer science), é frequente ver estas demonstrações designadas por "casos de estudo" (case studies). Note-se que estes 'casos de estudo' não têm nada a ver com os estudos de caso referidos na tabela 1.

Enc. Bibli: R. Eletr. Bibliotecon. Ci. Inf., Florianópolis, n. esp., $2^{\circ}$ sem. 2010. ISSNe 1518-2924.
} 
ambiente de teste implica uma definição clara dos critérios de medição da eficácia ou eficiência e envolve a utilização de testes normalizados.

No caso da área de TSI, prova de conceito e benchmarking são mais frequentemente utilizados para validar contributos tecnológicos que se enquadram no grupo das TI do corpo de conhecimento da área. Quando o elemento tecnológico em causa corresponde a um método ou a outra forma de tecnologia cuja aplicação envolve uma forte componente de acção humana, torna-se difícil transpor a situação de utilização de tecnologia para um ambiente laboratorial. Em tais casos há que recorrer a métodos de campo.

Poderá dizer-se que a lista de métodos de I\&D de campo apresentada está ordenada por ordem decrescente do nível de capacidade de controlo que o investigador tem sobre os factores considerados relevantes. No caso da experiência de campo, o investigador controla alguns factores procurando verificar a existência de alguma relação de causalidade. Já nos restantes métodos tal controlo não é possível de efectuar. Assim, o investigador limita-se a medir o valor de variáveis que considerou relevantes. Nas sondagens, o investigador conduz o seu estudo inquirindo um número suficiente de sujeitos por forma a poder tirar conclusões estatisticamente significativas sobre a existência de correlações entre variáveis. Mas está fora do seu alcance fazer variar o valor das variáveis dependentes. No caso dos estudos de caso ou da investigação-acção, o investigador conduz o seu estudo num ambiente em que não só não pode controlar variáveis como ainda, pelo facto de o estudo assentar em casos, os resultados obtidos não são generalizáveis. De qualquer modo, estes métodos suportam a condução de estudos que possibilitam a obtenção de um nível de compreensão dos fenómenos que poderá constituir um contributo significativo para a área.

No caso da investigação-acção, acresce ainda uma nova restrição. O investigador é simultaneamente parte do objecto de estudo, desempenhando parte activa no fenómeno em estudo. Fica assim comprometida a independência entre investigador e objecto investigado, um dos fundamentos da qualidade do processo de investigação. No entanto, são diversas as situações em que a exclusão deste método de I\&D implicaria o abdicar do estudo de determinado fenómeno. No caso da área de TSI, a investigação-accção é particularmente útil na validação da eficácia e eficiência dos métodos, técnicas e ferramentas necessárias ao trabalho dos engenheiros e gestores de TSI.

Qualquer dos métodos apresentados como de campo são amplamente usados nas ciências sociais e organizacionais. São também comuns na área de TSI para o estudo de fenómenos que ocorrem no contexto organizacional e ainda no desenvolvimento de tecnologia (sobretudo métodos) cuja aplicação ocorre em contexto organizacional.

Será razoável afirmar que os métodos referidos nesta secção são os principais métodos que permitem uma validação empírica de novos contributos para o conhecimento da área científica de TSI. No entanto, de modo algum esgotam o conjunto de métodos que têm vindo a ser usados em actividades de I\&D enquadráveis na área de TSI. Considerando a importância dos métodos e técnicas de trabalho no corpo de conhecimento da área, será razoável referir uma outra via para a sua validação - os painéis de especialistas. Quando está em causa a criação de novos métodos e técnicas, por exemplo, é frequente os investigadores constituírem um painel de especialistas a quem recorrem por forma a obterem opiniões fundamentadas. $\mathrm{O}$ processo de obtenção das opiniões de especialistas pode inclusivamente ser estruturado por forma a facilitar a obtenção de consensos como é o caso dos estudos Delphi. 


\section{CONCLUSÃo}

O mosaico de objectos de interesse, de fenómenos relevantes e de métodos de I\&D que constitui a área científica de TSI ganha coerência quando é perspectivado na óptica das necessidades de conhecimento dos profissionais de TSI.

Facilitar, ou mesmo promover, a contínua transformação das organizações através da adopção e exploração de TI é algo que exige intervenção a vários níveis: a nível dos indivíduos e das situações de trabalho em que se envolvem; a nível dos processos organizacionais, envolvendo indivíduos e grupos que por vezes trabalham num espírito de competição; a nível da organização, obrigando pois a uma perspectiva global, integrada e coerente da entidade organizacional. Por outro lado, as profissões de TSI envolvem interacção com toda a gama de papeis organizacionais.

Desta multiplicidade de objectos decorre a necessidade de recorrer a saberes construídos em várias áreas científicas, combinando-os por forma a conseguir uma base sólida, cientificamente validada, que sustente a acção dos profissionais da área.

O alargado âmbito do corpo de conhecimento da área de TSI, leva a que os profissionais de TSI possam ser vistos como generalistas, no sentido em que precisam de lidar com uma vasta cultura que transcende as fronteiras estabelecidas de várias outras aras científicas. No entanto, e considerando que aquele corpo de conhecimento é para ser aplicado na resolução de problemas bem específicos das organizações ou da sociedade, aquela generalidade constitui a especialização dos engenheiros e gestores de TSI.

Não será no entanto possível a uma única pessoa, abarcar extensivamente todas as facetas do corpo de conhecimento da área. Assim, depois de uma formação básica na área é normal que os profissionais de TSI definam carreiras profissionais que traduzem um percurso de focagem.

As várias actividades profissionais associadas aos engenheiros e gestores de TSI, exigindo embora um profundo conhecimento das TI, não implicam necessariamente a produção de artefactos tecnológicos. É no entanto discutível se é possível conhecer profundamente as TI e as suas capacidades se não forem desenvolvidas competências de realização tecnológica. Assim, é importante que desde a sua formação inicial os candidatos a profissionais de TSI sejam treinados na construção de artefactos tecnológicos - aplicações informáticas.

A perspectiva apresentada neste artigo da área de TSI - uma área científica orientada às necessidades de conhecimento dos engenheiros e gestores de TSI - tem como consequência que os profissionais de TSI têm um importante papel a desempenhar no desenvolvimento do corpo de conhecimento da área. Sobretudo no que diz respeito ao grupo dos métodos, técnicas e ferramentas, os profissionais estão particularmente bem posicionados para conduzirem estudos e iniciativas que permitem o desenvolvimento de contributos para o corpo de conhecimento da área e/ou efectuar acções de validação do conhecimento. É assim importante que a formação de profissionais de TSI estimule o desenvolvimento de uma atitude crítica e reflexiva sobre o conhecimento e que, sobretudo numa fase de formação avançada, contemple a aprendizagem de métodos e técnicas de I\&D. Até porque o corpo de conhecimento das TSI tem vindo evoluir, reflectindo a evolução das TI, das organizações e da sociedade. Estamos assim face a uma área científica em emergência, que procura ainda as suas directrizes e 
quadros teóricos fundamentais. Uma área onde o conhecimento de ontem terá talvez que ser substituído por novo conhecimento e onde os referenciais de hoje terão que ser revistos.

\section{REFERENCIAS}

AMARAL, L. Formação superior em informática e sistemas de informação: generalidade vs especificidade nas novas profissões. In: Revista das I Jornadas de Informática de Gestão, Universdade do Minho, Azurém, 28 e 29 de Abril de 1994, 1994.

BACON, C. J.; FITZGERALD, B. A systemic framework for the field of information systems. The Data BASE for Advances in Information Systems, v. 32, n. 2, 2001, p 46-67.

BANVILLE, C.; LANDRY, M. Can the field of MIS be disciplined? Communications of the $\operatorname{ACM}(32: 1)$, January 1989 1989, pp 48-60.

CARR, N. The big switch: rewiring the world, from Edison to Google. W. W. Norton \& Company, 2008.

CARVALHO, J. Á.; AMARAL, L. Matriz de actividades: um enquadramento conceptual para as actividades de planeamento e desenvolvimento de sistemas de informação. Sistemas de Informação, n. 1, 1993, p. 37-48.

CARVALHO, J. Á.; RAMOS, I. Understanding information systems in organizations: from Anthony's framework to the organizational mind. In: Jubilee International Scientific Conference - Informatin Support to Business. Economy Academy D. A., Tesov, Department of Business Informatics, Svishtov, Bulgaria, 2006, p. 40-48.

EARL, M. J.; SKYRME, D. J. "Hybrid managers: what do we know about them? Journal of Information Systems, v. 2, n. 3, 1992, p. 169-187.

EIN-DOR, P.; SEGEV, E.. A classification of information systems: analysis and interpretation. Information Systems Research, v. 4, n. 2, 1993, p. 166-204.

GORGONE, J. T. et al. MSIS 2006: model curriculum and guidelines for graduate degree programs in information systems. Communications of AIS, 17, January: Article 1, 2006.

HARDAWAY, D.; MATHIEU, R. G.; WILL, R. A new mission for the information systems discipline. IEEE Computer, May 2008, 2008, p. 81-83.

KEEN, P. G. W. Shaping the future: business design through information technology Harvard. Business School Press, 1991.

KHAZANCHI, D.; MUNKVOLD, E. Is information systems a science? An inquiry into the nature of the information systems discipline. Database for Advances in Information Systems, v. 31, n. 3, 2000, p. 24-42.

NEVO, S.; NEVO, D.; EIN-DOR, P. Thirty years of IS research: core artifacts and academic identity. Communications of AIS, v.25. n. 24, 2009, p. 221-242.

NIEDERMAN, F. But is it MIS? Communications of AIS, v.20, n.6, 2007, p. 26-32.

PORTER, M. E. Competitive advantage: creating and sustaining superior peformance. The Free Press, 1985.

RAMOS, I.; CARVALHO, J. A. Organizacional mind: a new perspectiva on knowledge management. In: Knowledge Management: theoretical foundations. A. Koohang; K. Harman (eds.). Informing Science Press, 2008. 
RAMOS, I.; CARVALHO, J. Á. Reinventing the future: a study of the organizational mind. In: IFIP International Conference on "The past and future of Information Systems: 19762006 and beyond”. (as part of IFIP World Computing Conference), Santiago, Chile, 2006.

RAMOS, I.; CARVALHO, J. Á. The representational capabilities of the organization: a new perspective on knowledge management. In: SoftWars 2007: Conference on Social, Organizational and Economic Impact of IT, Lisbon, Portugal, 2007.

SIDOROVA, A. et al.. Uncovering the intellectual core of the information systems discipline. MIS Quarterly, v. 32, n. 3, September 2008, p. 467-482.

SIMON, H. A. The Sciences of the Artificial. The MIT Press, UMo, 1981.

TOPI, H. et al. IS 2010: curriculum guidelines for undergraduate degree programs in information systems. In: Conference On Information Technology Education (formerly CITC). Proceedings of the 2010. Midland, Michigan, USA, 2010, p. 1-8.

WALLACE, K. M. Engineering design research? In: JACQUES, R.; POWELL, J. A. (eds.). Design, science: method, proceedings of the 1980. Design Research Society, Westbury House, 1981, p. 62-66.

\begin{abstract}
Information systems and technology (IST) is the scientific area of reference for those interested, academic or professionally, in the adoption and exploitation of information technology within organizations or society. IST emerged as a consequence of the importance that IT has assumed in human activities that involve some form of information processing. Given its strong association with other areas, its boundaries are difficult to define. The activities of IST professionals and their knowledge needs are used in this article as the criteria to define the scope of the IST scientific area. So, after a characterization of the professional activities of IST, we present the major components of the body of knowledge and the main R\&D methods used in the production of new scientifically valid knowledge in the area.
\end{abstract}

KEYWORDS: Information technology. Information systems. Professional profiles. Knowledge Organization.

Originais recebidos em: 26/07/2010

Aceito para publicação em: 29/10/2010

Enc. Bibli: R. Eletr. Bibliotecon. Ci. Inf., Florianópolis, n. esp., $2^{\circ}$ sem. 2010. ISSNe 1518-2924 